J. Lake Sci.(湖泊科学), 2020, 32(2): 380-394

DOI 10. 18307/2020. 0208

(c) 2020 by Journal of Lake Sciences

\title{
珠江下游浮游细菌群落结构的时空分布特征”
}

\author{
杜宛璘 ${ }^{1,2}$, 孙金辉 ${ }^{2}$, 麦永湛 ${ }^{1}$, 赖子尼 $^{1}$, 贾慧娟 ${ }^{1,3}$, 葛大艳 ${ }^{1,4}$, 王 超 ${ }^{1 * *}$ \\ (1:中国水产科学研究院珠江水产研究所,广州 510380) \\ ( 2 : 天津农学院, 天津市水产生态及养殖重点实验室, 天津 300384) \\ (3: 上海海洋大学水产与生命学院, 上海 201306) \\ (4: 上海海洋大学生态与环境学院, 上海 201306)
}

摘 要: 浮游细菌群落对河流变化具有高度响应性, 并可能影响河流生境的生物地球化学过程. 因此, 了解浮游细菌群落 的时空特征, 阐明其在河流生态系统中的生态功能具有重要科学意义.于 2016 年 6 月和 12 月对珠江下游浮游细菌群落 结构的时空特征进行调查研究, 并采用 $16 \mathrm{~S}$ rRNA 高通量测序技术对样品组分进行分析. 结果表明细菌群落主要由变形 菌门(Proteobacteria)、放线菌门(Actinobacteria)、拟杆菌门(Bacteroidetes)、厚壁菌门(Firmicutes)、疮微菌门( Verrucomicrobia) 和蓝细菌门 (Cyanobacteria) 组成. 其中变形菌门相对丰度最高, 主要包括 $\beta$-变形菌纲 (Betaproteobacteria)、 $\alpha$-变形菌纲 (Alphaproteobacteria) 和 $\gamma$-变形菌纲 (Gammaproteobacteria). 季节上, 丰水期 Shannon-Wiener 和 Chao 1 多样性指数高于枯 水期,其中芽孢杆菌纲 (Bacilli) 和黄杆菌纲 (Flavobacteriia) 差异显著; 空间上,珠江下游可分为西江沿线、珠三角河网中部 和广州市周边 3 个区域. 采用 $\mathrm{RDA}$ 分析表明, 水温 ( WT)、溶解氧 $(\mathrm{DO})$ 、磷酸盐 $\left(\mathrm{PO}_{4}^{3-}-\mathrm{P}\right)$ 、硅酸盐 $\left(\mathrm{SiO}_{4}^{2-}-\mathrm{Si}\right) 、$ 总磷 $(\mathrm{TP})$ 和透明度 $(\mathrm{SD})$ 是驱动细菌群落变化最显著的环境因子, 可影响细菌的增殖代谢. 其中 WT 和 SD 是影响季节差异的重要 因素, 将丰水期和枯水期区分开; 而 DO、化学需氧量 ( COD ) 和营养盐 $\left(\mathrm{PO}_{4}^{3-}-\mathrm{P} 、 \mathrm{SiO}_{4}^{2-}-\mathrm{Si} 、 \mathrm{TP}\right)$ 是影响空间差异的重要因素, 将西江沿线、珠三角河网中部和广州市周边区分开. PICRUSt 功能预测分析表明, 转运体( Transporters)、 $\mathrm{ABC}$ 转运体 ( $\mathrm{ABC}$ transporters)、DNA 修复和重组蛋白( DNA repair and recombination proteins) 等是珠江下游浮游细菌群落所表达的主要功 能, 其中转运体和 $\mathrm{ABC}$ 转运体功能丰水期明显高于枯水期. 研究结果可为珠江下游生态环境保护提供科学参考依据.

关键词: 浮游细菌; 珠江下游; 高通量测序;时空分布;群落结构

\section{Spatial and temporal distribution characteristics of bacterioplankton community structure in the downstream of Pearl River*}

\author{
DU Wanlin ${ }^{1,2}$, SUN Jinhui ${ }^{2}$, MAI Yongzhan ${ }^{1}$, LAI Zini ${ }^{1}$, JIA Huijuan ${ }^{1,3}$, GE Dayan ${ }^{1,4} \&$ WANG Chao ${ }^{1 * *}$ \\ (1: Pearl River Fisheries Research Institute, Chinese Academy of Fishery Science, Guangzhou 510380, P.R.China) \\ (2: Tianjin Agricultural University, Tianjin Key Lab of Aqua-Ecology and Aquaculture, Tianjin 300384, P.R.China) \\ (3: College of Fisheries and Life Science, Shanghai Ocean University, Shanghai 201306, P.R.China) \\ (4: Ecology and Environmental Science, Shanghai Ocean University, Shanghai 201306, P.R. China)
}

Abstract: The bacterioplankton community is highly responsive to river changes and may affect the biogeochemical processes of river habitats. Consequently, understanding the temporal and spatial characteristics of bacterioplankton communities and revealing their ecological functions in river ecosystems have important scientific significance. In June and December 2016, the research team investigated the temporal and spatial characteristics of the bacterioplankton community structure in the downstream of Pearl River, and analyzed the sample components using 16S rRNA high-throughput sequencing technology. The dominant bacterial community included Proteobacteria, Actinobacteria, Bacteroidetes, Firmicutes, Verrucomicrobia and Cyanobacteria. The relative abundance of Proteobacteria was the highest, and its main components included Betaproteobacteria, Alphaproteobacteria and Gammaproteobacte-

* 2019-07-01 收稿; 2019-09-11 收修改稿.

广州市科技计划项目 (201707010310) 和中国水产科学研究院基本科研业务费项目 (2018SJ-ZH01, 2019XT07, 2019XT0701) 联合资助.

** 通信作者;E-mail : chaowang80@ 163.com. 
ria. The diversity index of Shannon-Wiener and Chao 1 in the wet season was higher than in the dry season, and the difference between Bacilli and Flavobacteriia was significant. The downstream of Pearl River can be divided into the Xijiang River, the middle of Pearl River Delta and the surrounding areas of Guangzhou. RDA analysis showed that water temperature(WT), dissolved oxygen (DO), phosphate $\left(\mathrm{PO}_{4}^{3-}-\mathrm{P}\right)$, silicate $\left(\mathrm{SiO}_{4}^{2-}-\mathrm{Si}\right)$, total phosphorus ( TP ) and transparency ( $\mathrm{SD}$ ) were the most significant environmental factors driving the change in bacterial community, and may have affected the increment metabolism of bacteria. Water temperature and transparency are important factors affecting seasonal differences. The differences between wet and dry seasons; DO; chemical oxygen demand ( $\mathrm{COD})$; and nutrients $\left(\mathrm{PO}_{4}^{3-}-\mathrm{P}, \mathrm{SiO}_{4}^{2-}-\mathrm{Si}, \mathrm{TP}\right)$ were important factors affecting spatial differences; these distinguished the mainstream of the Xijiang River, the middle of Pearl River Delta and the surrounding areas of Guangzhou. PICRUSt functional predictive analysis showed that Transporters, ABC transporters, DNA repair and recombination proteins were the main functions expressed by the bacterioplankton community in the downstream of Pearl River. The ABC transporters and Transporters were significantly higher in the wet season than in the dry season. The research results can provide a scientific reference for the ecological environment protection in the downstream of Pearl River.

Keywords: Bacterioplankton; the downstream of Pearl River; high-throughput sequencing; temporal and spatial characteristics; community structure

河流具有高度的环境异质性和微生物群落多样性, 是碳氮等元素转化的重要场所. 浮游细菌作为河流 生态系统中的重要组成部分在河流生物地球化学循环中发挥着重要作用 ${ }^{[1]}$,其中包括固氮、脱氮、固碳、硫 化物氧化 ${ }^{[2]}$ 和降解水体污染物 ${ }^{[3]}$ 等多种功能. 已有研究表明, 河流浮游细菌群落组成受时间、空间、温度、 氮、磷、 $\mathrm{pH}$ 、溶解氧等 ${ }^{[4-5]}$ 环境因子的影响, 在时空分布上呈现显著差异, 而细菌群落组成差异又决定了细菌 群落在河流生态系统中发挥不同的功能. 因此, 阐明浮游细菌群落时空分布及其环境响应机制, 有助于深人 了解河流内部环境变化规律,揭示细菌群落组成与河流生态系统功能之间的关系. 目前有很多学者对河流 生态系统中的浮游细菌群落进行了研究, 例如九龙汇 ${ }^{[4]} 、$ 密西西比河 ${ }^{[6]} 、$ 长汇 $^{[7]} 、$ 东江 ${ }^{[8]}$ 等, 然而迄今为止, 有关我国珠江下游浮游细菌群落的研究仍鲜有报道.

珠江是中国南方最大的水系, 是中国境内第三长河流. 珠江是沿江地区人们生活、农业、工业用水的主 要来源 ${ }^{[9]}$. 珠江下游流经人口密集、经济发达的珠三角城市群和粤港澳大湾区, 常年受工农业污染以及居民 生活污水排放的影响,珠江下游生态环境遭到严重破坏. 近年研究表明,珠江流域不同地区都存在污染物浓 度逐年升高的趋势 ${ }^{[10]}$, 且珠江下游河网区域重金属污染程度较高 ${ }^{[11]}$, 这极大限制了珠江水资源的可持续利 用. 目前有关珠江流域生态环境的相关研究主要涉及土壤 ${ }^{[12]}$ 、水质 ${ }^{[13]}$ 、浮游植物 ${ }^{[14]}$ 和底栖动物 ${ }^{[15]}$, 有关浮 游细菌群落的研究相对较少.

高通量测序技术因其快速、准确、大批量、并且免于实验室培育等优点 ${ }^{[16-17]}$, 已经成为环境微生物学和 微生物生物地理学的主要研究技术手段, 并被广泛应用于湿地、土壤和生物膜等复杂环境中微生物群落结 构的研究 ${ }^{[18-20]}$. 本文采用 $16 \mathrm{~S} \mathrm{rDNA}$ 扩增子测序方法对珠江下游采集的水体样品进行高通量测序, 结合多种 生信统计方法, 探索珠江下游浮游细菌群落动态变化, 以期更全面地了解珠江下游水体状况. 我们假设, 珠 江下游浮游细菌受环境因子影响将在群落结构上呈现明显差异, 这种差异有助于确定珠江下游浮游细菌群 落与环境特征之间的关系. 因此, 本文旨在了解珠江下游浮游细菌群落多样性及分布情况; 确定影响浮游细 菌群落多样性及分布的关键驱动因子, 为珠江流域水生生态环境保护以及珠江水域污染的生态预警, 提供 科学资料和理论依据.

\section{1 材料与方法}

\section{1 调查时间和站位}

于 2016 年 6 月 (丰水期) 和 2016 年 12 月 (枯水期) 对珠江下游水域进行野外调查. 在该水域共布设 16 个采样站位, 基本覆盖了西江沿线、珠三角河网中部和广州市周边, 具体站位如图 1 所示. 包括封开 (FK)、

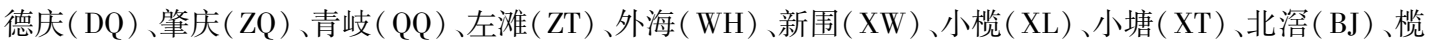
核 (LH)、横沐 (HL)、陈村 (CC)、市桥 (SQ)、莲花山 ( LHS)、珠江桥 (ZJQ). 其中封开、德庆、肇庆、青岐、左 滩、外海、新围位于西江沿线, 小榄、小塘、北滘、榄核、横沥、陈村和市桥位于珠三角河网中部, 珠江桥和莲花 
山位于广州市周边.

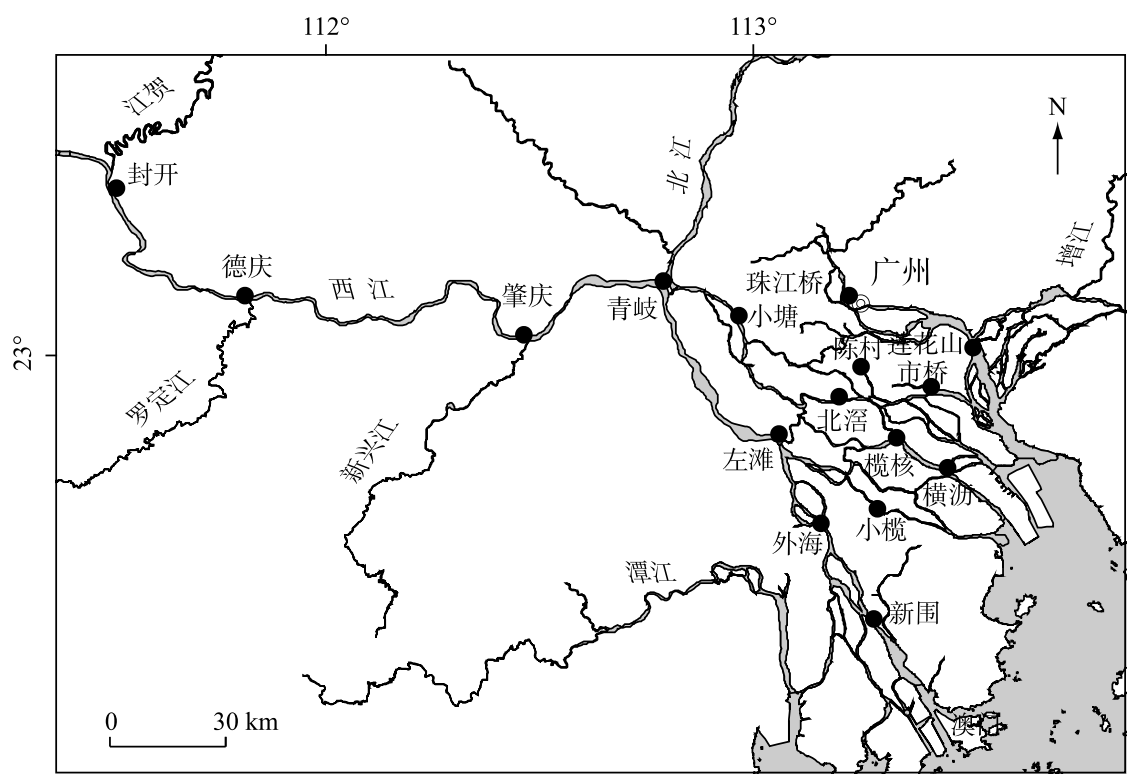

图 1 珠江下游调查部位分布

Fig. 1 Sampling sites in the downstream of Pearl River

\section{2 样品采集与处理}

使用 $5 \mathrm{~L}$ 有机玻璃采水器采集表层 (距离水面 $0.5 \mathrm{~m}$ ) 水样 $3 \mathrm{~L}$. 其中 $2 \mathrm{~L}$ 水样采集后立即转移到无菌取 样袋中 (TWIRL EM ${ }^{\circledR}$, LABPLAS INC., Quebec, Canada), 放于 $4^{\circ} \mathrm{C}$ 冰箱下冷藏, 尽快运回实验室. 取 $1.5 \mathrm{~L}$ 水样 等分为 3 份 (生物学重复, 避免误差), 分别经 $200 \mu \mathrm{m}$ 尼龙膜 (NY-05, Switzerland) 初滤去除大型浮游生物和 杂质, 再通过 $0.22 \mu \mathrm{m}$ 孔径的聚碳酸酯滤膜( PALL, USA) 过滤, 并迅速将滤膜转移至 $10 \mathrm{~mL}$ 无菌离心管, 保 存在 $-80^{\circ} \mathrm{C}$ 条件下用于 DNA 提取. 其余样品等分为 2 份, 一份经 $0.45 \mu \mathrm{m}$ 孔径醋酸纤维素滤膜( Whatman, USA) 过滤后保留水样; 另一份按照《水质样品的保存和管理技术规定》( HJ 493-2009) 标准加人固定剂于 $4^{\circ} \mathrm{C}$ 保存, 用于水化学分析.

\section{3 环境因子数据收集}

使用 YSI Professional Plus 手持多参数水质分析仪 (YSI INC., USA) 现场测定水温 (WT)、pH、溶解氧 $(\mathrm{DO})$ 、氧化还原电位 $(\mathrm{ORP})$ 、化学需氧量 $(\mathrm{COD})$ 和盐度 $(\mathrm{S})$ 参数; 透明度盘测定透明度 $(\mathrm{SD})$; 经 $0.45 \mu \mathrm{m}$ 滤 膜过滤和加固定剂的水样, 按照《海洋监测规范第 4 部分: 海水分析》(GB 17378.4-2007) 规定的方法, 测定 磷酸盐 $\left(\mathrm{PO}_{4}^{3-}-\mathrm{P}\right)$ 、总磷 $(\mathrm{TP})$ 、硝酸盐 $\left(\mathrm{NO}_{3}^{-}-\mathrm{N}\right)$ 、亚硝酸盐 $\left(\mathrm{NO}_{2}^{-}-\mathrm{N}\right)$ 、铵盐 $\left(\mathrm{NH}_{4}^{+}-\mathrm{N}\right)$ 、氨 $\left(\mathrm{NH}_{3}-\mathrm{N}\right)$ 、总氮 $(\mathrm{TN})$ 和 硅酸盐 $\left(\mathrm{SiO}_{4}^{2-}-\mathrm{Si}\right)$ 等浓度. 环境因子显著性分析采用 Excel 中的单因素方差分析法.

\subsection{DNA 提取、聚合酶链式反应 (PCR) 和高通量测序}

水体样品总 DNA 采用 DNeasy PowerWater ${ }^{\circledR}$ Kit 试剂盒( MO BIO Laboratories, United States) 提取, 按照生 产商提供的说明书进行操作. 用分光光度计 (NanoDrop ND-2000, USA) 检测 DNA 纯度和浓度, 并通过 $1 \%$ 琼 脂糖凝胶电泳进行观察. 利用 515 正向引物 ( $5^{\prime}$-GTGCCAGCMGCCGCGG-3') 和 806 反向引物 ( $5^{\prime}$-GGACTACHVGGGTWTCTAAT- $\left.3^{\prime}\right)^{[21]}$ 扩增细菌 $16 \mathrm{~S}$ rRNA 基因的 V4 高变区. 在含有 $10 \mu \mathrm{L} 5 \times$ TransStart $^{\circledR}$ FastPfu Fly 缓冲液, $5 \mu \mathrm{L} \operatorname{dNTPs}(2.5 \mathrm{mmol} / \mathrm{L}), 2 \mu \mathrm{L}$ 正向引物 $(5 \mu \mathrm{mol} / \mathrm{L}), 2 \mu \mathrm{L}$ 反向引物 $(5 \mu \mathrm{mol} / \mathrm{L}), 1 \mu \mathrm{L} \mathrm{Trans}-$

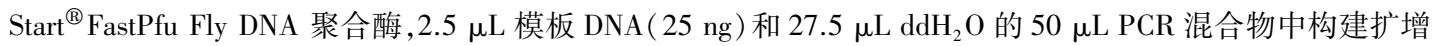
子文库. PCR 反应条件为: $95^{\circ} \mathrm{C} 1 \mathrm{~min} ; 95^{\circ} \mathrm{C} 30 \mathrm{~s}, 55^{\circ} \mathrm{C} 30 \mathrm{~s}, 72^{\circ} \mathrm{C} 45 \mathrm{~s}$, 共 27 个循环; $72^{\circ} \mathrm{C} 10 \mathrm{~min} ; 4^{\circ} \mathrm{C}$ 终止反 应. 对每份样品所制备的一式 3 份的 PCR 产物等体积混合, 进一步通过 $1 \%$ 琼脂糖凝胶检测 PCR 产物纯化 
效果,最后在 Illumina 二代测序平台( Illumina Inc, CA, USA) 进行测序.

\section{5 生信分析}

双向测序完成后下机的测序片段 (reads) 经 FLASH (version 1.2.11) ${ }^{[22]}$ 组装, 并由 QIIME (version

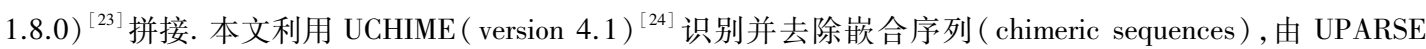
(version 7.0.1001) ${ }^{[25]}$ 进行可操作分类单元 (OTU, operational taxonomic units) 聚类 (序列一致性设定为 $97 \%$ ), 以 0.8 置信度阈值对 OTU 进行注释, 并将所有叶绿体、真核生物、未知序列以及 OTU 单体 (singleton) 去除.

通过 RStudio 程序包 vegan 的 diversity 函数计算香农-威尔指数 (Shannon-Wiener index) 和 Chao 1 指数 (Chao 1 index). 采用非度量多维尺度 (NMDS, nonmetric multidimensional scaling) 和相似性分析 (ANOSIM, analysis of similarities) 方法分析细菌群落组间差异及时空分布特征. 基于群落 Bray-Curtis 相异度, 采用 RStudio 程序包 vegan 和 grid 进行 CCA/RDA 分析,评估细菌与环境因子之间的关系.

\section{6 功能预测分析}

使用 PICRUSt 软件,基于 OTU 的物种注释和丰度信息,将 KEGG 数据库中已有基因组的原核生物 $16 \mathrm{~S}$ rRNA 序列与 SILVA ${ }^{[26]}$ 数据库中 $16 \mathrm{~S}$ rRNA 序列进行关连, 然后将 KEGG 数据库已有的原核物种基因组进行 序列打断, 利用 UProC( version 1.2.0) 对所有基因组的 $\mathrm{KO}$ 序列进行统计. 最后利用 $16 \mathrm{~S}$ 的拷贝数对物种数 目进行校正,最终实行 KEGG 预测以及 $\mathrm{KO}$ 丰度统计,从而获得所测基因的功能预测信息. 原始数据上传到 NCBI-SRA 数据库,登陆号:PRJNA550236.

\section{2 结果与分析}

\section{1 珠江下游水体理化特征}

珠江下游 16 个站位的水体理化特征如表 1 所示. 季节特征显示, WT、SD 和 ORP 的季节间差异比较明 显, $P$ 值均小于 0.01 . 丰水期的 WT 和 ORP 明显高于枯水期, $\mathrm{SD}$ 则相反; 营养盐 $\left(\mathrm{PO}_{4}^{3-}-\mathrm{P} 、 \mathrm{TP} 、 \mathrm{NO}_{3}^{-}-\mathrm{N} 、 \mathrm{NO}_{2}^{-}-\mathrm{N}\right.$ 、 $\left.\mathrm{NH}_{4}^{+}-\mathrm{N} 、 \mathrm{NH}_{3}-\mathrm{N} 、 \mathrm{TN} 、 \mathrm{SiO}_{4}^{2-}-\mathrm{Si}\right)$ 浓度一般呈现枯水期高于丰水期的规律. 空间分布特征显示, 广州市周边站位 的营养盐浓度一般明显高于其他站位 $(P<0.05)$, DO 则相反 $(P<0.01)$. 且 DO 浓度的空间分布格局基本呈 现沿西江沿线站位、珠三角河网中部、广州市周边递减的趋势, COD 与其相反. 其他环境因子的空间分布未 呈现明显规律.

\section{2 珠江下游浮游细菌群落结构组成}

测序结果显示, 质量过滤后, 珠江下游 16 个站位所采集的 48 个表层水样品, 一共获得 4389036 个有效 reads, 并注释 268004 个 OTUs, 平均每个样本的 OTU 数目为 $3125 \pm 1632$.

在门分类水平上,检测到的前 15 个门类, 季节特征显示变形菌 (Proteobacteria) 在丰水期和枯水期均为 最优势门类 (图 2), 相对百分比分别为 50.04\% 和 52.62\%. 此外, 丰水期优势门类的多样性高于枯水期, 除了 两个季节均占优势的变形菌、放线菌 (Actinobacteria) 和拟杆菌 (Bacteroidetes) 外, 厚壁菌 (Firmicutes) 和蓝细 菌 (Cyanobacteria) 在丰水期的个别站位也会形成较大的优势 (图 2A). 空间特征显示, 变形菌在丰水期的空 间分布呈现河网中部的相对丰度高于西江沿线和广州市周边 (图 2A), 而其在枯水期的空间分布则呈相反 趋势 (图 2B). 此外, 厚壁菌在丰水期的西江沿线和河网中部的个别站位, 相对丰度会超过变形菌 (图 2A).

在纲分类水平上, $\beta$-变形菌 (Betaproteobacteria) 在丰水期和枯水期均为最优势菌纲 (图 3), 相对百分比 分别为 $27.89 \%$ 和 $25.62 \%$. 此外, 丰水期特有的优势菌纲有芽狍杆菌 (Bacilli) 和蓝细菌 (Cyanobacteria) (图 $3 \mathrm{~A}$ ), 而枯水期特有的优势菌纲有黄杆菌 (Flavobacteriia) 和 $\varepsilon$-变形菌 (Epsilonproteobacteria) (图 3B). 空间特 征显示, 丰水期放线菌呈西江沿线 $>$ 河网中部 $>$ 广州市周边的趋势, $\alpha$-变形菌 (Alphaproteobacteria) 、 $\gamma$-变形菌 (Gammaproteobacteria) 和芽狍杆菌在西江沿线和河网中部个别站位成为最优势菌纲 (图 3A), 蓝细菌在广州 市周边站位相对丰度明显升高; 枯水期 $\beta$-变形菌在西江沿线的相对丰度波动较大, 而在河网中部和广州市 周边站位较稳定 (图 3B).

\section{3 珠江下游细菌群落结构多样性}

Shannon-Wiener 指数和 Chao 1 指数分析结果显示, 珠江下游浮游细菌群落的季节差异不明显, 丰水期 
表 1 珠江下游表层水体环境特征

Tab.1 Characteristics of water environment factors in the downstream of Pearl River

\begin{tabular}{|c|c|c|c|c|c|c|c|c|c|c|c|c|c|c|c|c|}
\hline & 样品 & $\begin{array}{c}\text { WT/ } \\
{ }^{\circ} \mathrm{C}\end{array}$ & $\begin{array}{l}\mathrm{SD} / \\
\mathrm{cm}\end{array}$ & $\mathrm{pH}$ & $\begin{array}{c}\mathrm{DO} / \\
(\mathrm{mg} / \mathrm{L})\end{array}$ & $\begin{array}{c}\text { ORP/ } \\
\mathrm{mV}\end{array}$ & $\begin{array}{l}\mathrm{PO}_{4}^{3-}-\mathrm{P} / \\
(\mathrm{mg} / \mathrm{L})(\end{array}$ & $\begin{array}{c}\mathrm{TP} / \\
(\mathrm{mg} / \mathrm{L})\end{array}$ & $\mathrm{NO}_{3}^{-}-\mathrm{N} /$ & $\mathrm{NO}_{2}^{-}-\mathrm{N} /$ & $\mathrm{NH}_{4}^{+}$ & $\begin{array}{l}\mathrm{NH}_{3}-\mathrm{N} / \\
(\mathrm{mg} / \mathrm{L})\end{array}$ & $\begin{array}{l}\mathrm{TN} / \\
\mathrm{mg} / \mathrm{L})\end{array}$ & $\begin{array}{l}\mathrm{SiO}_{4}^{2-}-\mathrm{Si} / \\
(\mathrm{mg} / \mathrm{L})\end{array}$ & $\begin{array}{l}\mathrm{COD} / \\
(\mathrm{mg} / \mathrm{L})\end{array}$ & $\begin{array}{c}\text { 盐度/ } \\
\% 0\end{array}$ \\
\hline \multirow[t]{16}{*}{ 丰水期 } & 封开 & 32.5 & 10 & 7.6 & 7.9 & 115.1 & 0.019 & 0.038 & 1.580 & 0.033 & 0.289 & 0.010 & 2.868 & 2.682 & 2.29 & 0.89 \\
\hline & 德庆 & 28.8 & 10 & 7.4 & 7.9 & 194.5 & 0.023 & 0.046 & 1.590 & 0.002 & 0.141 & 0.003 & 2.604 & 2.589 & 2.36 & 0.72 \\
\hline & 肇庆 & 27.3 & 10 & 7.9 & 7.3 & 179.4 & 0.019 & 0.038 & 1.470 & 0.028 & 0.332 & 0.020 & 2.775 & 2.682 & 1.97 & 0.68 \\
\hline & 青岐 & 25.1 & 15 & 7.9 & 6.5 & 185.3 & 0.057 & 0.114 & 1.410 & 0.155 & 0.289 & 0.015 & 2.804 & 2.869 & 2.32 & 0.63 \\
\hline & 左滩 & 27.1 & 15 & 8.0 & 7.1 & 149.2 & 0.033 & 0.066 & 1.350 & 0.094 & 0.165 & 0.012 & 2.432 & 2.776 & 1.51 & 1.27 \\
\hline & 外海 & 31.0 & 30 & 7.1 & 7.4 & 114.6 & 0.024 & 0.048 & 1.900 & 0.013 & 0.008 & 0.000 & 2.882 & 2.589 & 1.92 & 1.14 \\
\hline & 新围 & 28.2 & 20 & 6.8 & 7.3 & 111.1 & 0.042 & 0.084 & 1.460 & 0.023 & 0.041 & 0.000 & 2.286 & 2.495 & 2.81 & 0.68 \\
\hline & 小榄 & 33.8 & 10 & 7.9 & 6.5 & 121.9 & 0.026 & 0.052 & 1.310 & 0.033 & 0.170 & 0.020 & 2.300 & 3.242 & 2.38 & 1.03 \\
\hline & 小塘 & 29.7 & 10 & 7.8 & 6.6 & 126.9 & 0.022 & 0.044 & 2.060 & 0.072 & 0.132 & 0.007 & 3.407 & 5.112 & 2.71 & 0.58 \\
\hline & 北滘 & 27.6 & 10 & 7.5 & 6.5 & 111.9 & 0.026 & 0.052 & 1.260 & 0.061 & 0.127 & 0.003 & 2.177 & 3.804 & 2.32 & 0.75 \\
\hline & 榄核 & 28.3 & 10 & 8.0 & 6.7 & 129.6 & 0.026 & 0.052 & 1.310 & 0.017 & 0.318 & 0.026 & 2.507 & 4.738 & 3.05 & 1.33 \\
\hline & 横沥 & 26.9 & 10 & 7.7 & 6.0 & 101.5 & 0.026 & 0.052 & 0.350 & 0.183 & 0.175 & 0.007 & 1.073 & 4.832 & 3.24 & 0.60 \\
\hline & 陈村 & 27.9 & 10 & 7.8 & 6.8 & 131.1 & 0.023 & 0.046 & 0.670 & 0.037 & 0.127 & 0.007 & 1.262 & 4.458 & 2.99 & 1.19 \\
\hline & 市桥 & 32.3 & 5 & 7.8 & 6.5 & 150.7 & 0.068 & 0.136 & 1.760 & 0.077 & 0.160 & 0.011 & 3.012 & 4.987 & 5.50 & 0.96 \\
\hline & 莲花山 & 31.1 & 10 & 7.9 & 4.3 & 135.2 & 0.062 & 0.124 & 3.640 & 0.197 & 0.189 & 0.015 & 6.062 & 5.112 & 4.49 & 1.41 \\
\hline & 珠江桥 & 30.7 & 10 & 7.7 & 2.5 & 142.8 & 0.093 & 0.186 & 4.060 & 0.226 & 1.703 & 0.083 & 9.108 & 8.477 & 4.47 & 0.75 \\
\hline \multirow[t]{16}{*}{ 枯水期 } & 封开 & 20.1 & 55 & 8.3 & 8.2 & 71.4 & 0.005 & 0.010 & 1.880 & 0.039 & 0.118 & 0.011 & 3.072 & 3.991 & 1.63 & 0.11 \\
\hline & 德庆 & 20.6 & 45 & 8.2 & 7.9 & 80.0 & 0.005 & 0.010 & 1.760 & 0.041 & 0.203 & 0.015 & 3.029 & 3.430 & 1.46 & 0.12 \\
\hline & 肇庆 & 22.6 & 45 & 8.3 & 7.9 & 118.5 & 0.005 & 0.010 & 1.860 & 0.044 & 0.175 & 0.018 & 3.146 & 4.271 & 1.41 & 0.12 \\
\hline & 青岐 & 20.8 & 40 & 8.0 & 6.9 & 77.8 & 0.013 & 0.026 & 1.840 & 0.078 & 0.208 & 0.010 & 3.204 & 7.168 & 2.37 & 0.13 \\
\hline & 左滩 & 20.8 & 55 & 8.4 & 7.7 & 74.1 & 0.027 & 0.054 & 1.770 & 0.089 & 0.141 & 0.017 & 3.026 & 3.710 & 1.72 & 0.12 \\
\hline & 外海 & 23.2 & 50 & 8.6 & 9.6 & 52.8 & 0.041 & 0.082 & 1.770 & 0.075 & 0.165 & 0.033 & 3.065 & 3.617 & 2.14 & 0.12 \\
\hline & 新围 & 21.2 & 60 & 8.3 & 7.1 & 70.1 & 0.013 & 0.026 & 1.700 & 0.127 & 0.499 & 0.048 & 3.561 & 6.794 & 1.94 & 0.14 \\
\hline & 小榄 & 20.6 & 50 & 8.4 & 7.5 & 82.9 & 0.037 & 0.074 & 1.820 & 0.124 & 0.246 & 0.028 & 3.327 & 3.804 & 1.86 & 0.14 \\
\hline & 小塘 & 19.7 & 70 & 8.5 & 7.5 & 59.8 & 0.042 & 0.084 & 1.730 & 0.104 & 0.456 & 0.060 & 3.525 & 3.991 & 1.75 & 0.12 \\
\hline & 北滘 & 18.0 & 70 & 8.4 & 7.9 & 52.8 & 0.052 & 0.104 & 1.780 & 0.111 & 0.508 & 0.051 & 3.675 & 4.178 & 2.20 & 0.12 \\
\hline & 榄核 & 19.8 & 60 & 8.3 & 7.7 & 87.9 & 0.043 & 0.086 & 1.890 & 0.106 & 0.737 & 0.066 & 4.199 & 4.364 & 2.20 & 0.13 \\
\hline & 横沥 & 20.5 & 45 & 8.3 & 6.7 & 73.6 & 0.057 & 0.114 & 1.860 & 0.089 & 0.346 & 0.032 & 3.491 & 3.897 & 2.17 & 0.14 \\
\hline & 陈村 & 19.0 & 50 & 8.3 & 6.6 & 58.3 & 0.058 & 0.116 & 2.130 & 0.108 & 1.046 & 0.087 & 5.057 & 4.551 & 2.59 & 0.13 \\
\hline & 市桥 & 19.7 & 40 & 8.1 & 5.1 & 59.3 & 0.083 & 0.166 & 2.080 & 0.129 & 1.160 & 0.065 & 5.151 & 4.271 & 2.99 & 0.17 \\
\hline & 莲花山 & 21.7 & 20 & 8.0 & 1.4 & 88.9 & 0.024 & 0.048 & 3.810 & 0.265 & 0.508 & 0.026 & 6.914 & 4.738 & 4.14 & 1.36 \\
\hline & 珠江桥 & 23.4 & 25 & 7.9 & 1.0 & 91.0 & 0.127 & 0.254 & 2.780 & 0.472 & 14.130 & 0.669 & 27.077 & 4.458 & 5.41 & 0.30 \\
\hline
\end{tabular}

略高于枯水期 (图 4).

采用基于归一化 OTUs 丰度的 NMDS 分析方法, 并结合 ANOSIM 的 $R$ 值进行 $\beta$ 多样性分析. ANOSIM 是 显示组间差异和组内差异的一个参数. $\beta$ 多样性分析结果表明, 珠江下游浮游细菌群落结构在空间尺度上 无显著差异 $(R=0.033, P=0.331)$, 而在时间尺度上呈现显著性差异 $(R=0.222, P=0.001)$. 所有站位被分为 4 组,丰水期和枯水期可以明显区分开,组 1 和组 3 为丰水期站位,组 2 和组 4 除丰水期的青岐和市桥两个 站位外,均为枯水期站位 (图 5). 其次每个季节在空间上可以分为两个组群, 丰水期的组 1 站位位于西江三 角洲, 组 3 位于北江三角洲; 枯水期的组 2 大部分站位位于广州市周边, 组 4 大部分位于西江沿线和珠三角 河网中部.

\section{4 珠江下游细菌群落结构的环境驱动因子}

对纲水平细菌群落与环境因子进行 RDA 分析(图 6). 方差分析检验( ANOVA test) 结果显示, 轴 $1(P=$ 

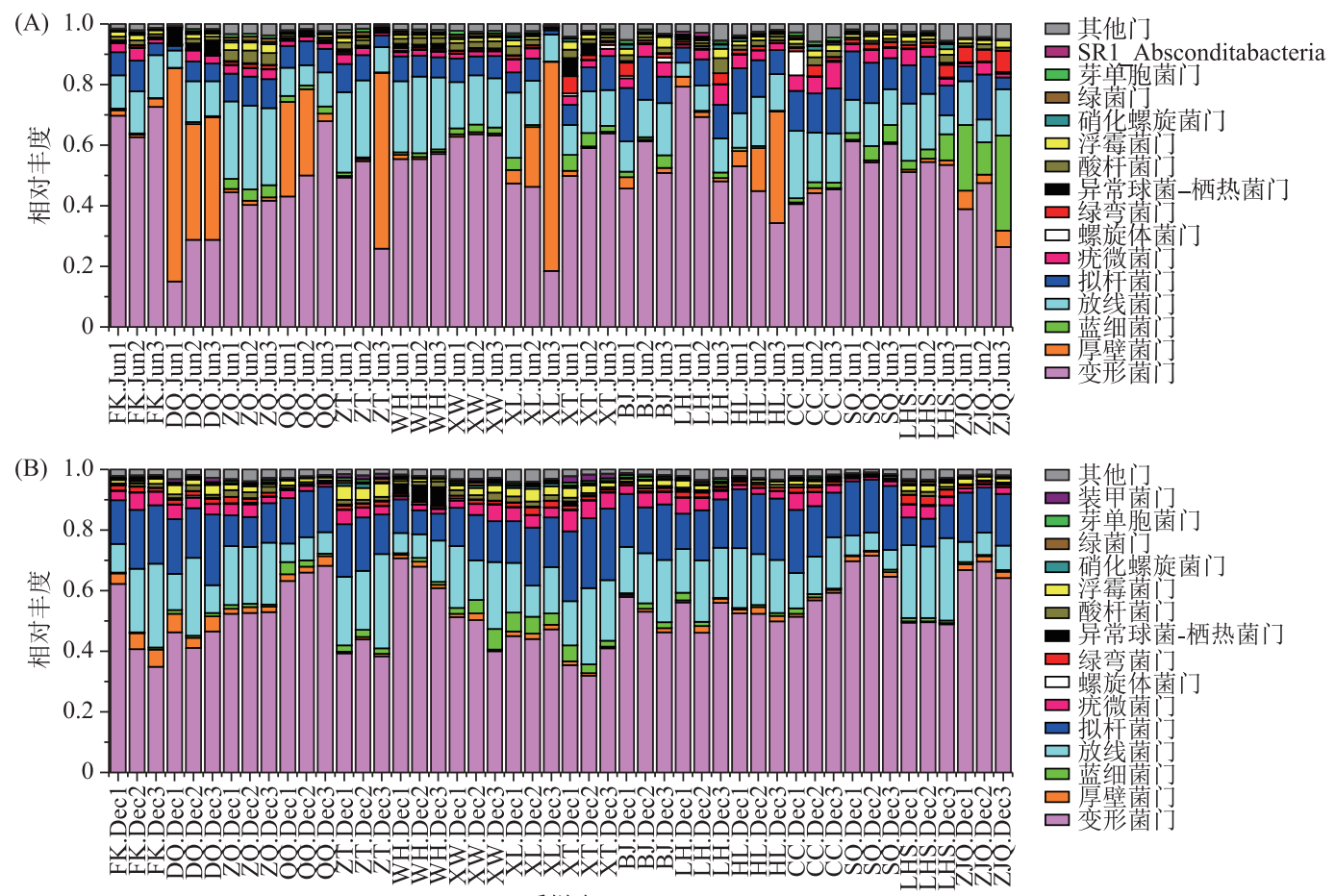

$\square$ 芽单胞菌门

$\square$ 绿菌门

口硝化螺旋菌门

$\square$ 浮需菌门

口酸杆菌门

算常球菌-栖热菌门

口绿弯菌门

螺旋体囷门

$\square$ 庱微菌门

$\square$ 拟杆菌!

$\square$ 蓝细菌门

口営壁菌门

变形菌门

采样点

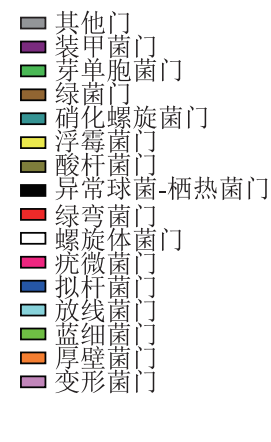

图 2 珠江下游浮游细菌丰水期 (A) 和枯水期 (B) 各门的相对丰度

(FK.Jun:封开丰水期;FK.Dec:封开枯水期;其他类同)

Fig. 2 Relative abundance of each phylum of bacterioplankton in wet season(A) and dry season (B) in the downstream of Pearl River

$0.001)$ 和轴 $2(P=0.035)$ 对关联性的影响显著. 轴 1 和轴 2 的特征值分别为 13.052 和 9.572 , 分别可解释所 有环境因子影响的 $30.02 \%$ 和 $22.02 \%$, 可较好地解释细菌群落组成与环境因子之间的关系. WT $\left(R^{2}=0.200\right.$, $P<0.01) 、 \mathrm{DO}\left(R^{2}=0.136, P<0.01\right) 、 \mathrm{PO}_{4}^{3-}-\mathrm{P}\left(R^{2}=0.095, P<0.01\right) 、 \mathrm{SiO}_{4}^{2-}-\mathrm{Si}\left(R^{2}=0.076, P<0.05\right) 、 \mathrm{TP}\left(R^{2}=\right.$ $0.072, P<0.05)$ 和 $\mathrm{SD}\left(R^{2}=0.072, P<0.05\right)$ 是驱动细菌群落变化最显著的环境因子 $(P<0.05)$. 基于轴 1 的 关联性结果显示, $\mathrm{WT}$ 和 $\mathrm{SD}$ 是影响季节差异的重要因素, 将丰水期和枯水期分开; 基于轴 2 的关联性结果显 示, DO、COD 和营养盐 $\left(\mathrm{PO}_{4}^{3-}-\mathrm{P} 、 \mathrm{SiO}_{4}^{2-}-\mathrm{Si} 、 \mathrm{TP}\right)$ 是影响空间差异的重要因素,将组 1 和组 3 分开、组 2 和组 4 分开.

将前 15 纲的细菌群落与环境因子进行 RDA 分析 (图 7), 轴 $1(P=0.034)$ 和轴 $2(P=0.621)$ 对关联性的 影响较大. 轴 1 和轴 2 的特征值分别为 2.235 和 0.880 ,分别可解释所有环境因子影响的 $44.43 \%$ 和 $17.49 \%$. 基于轴 1 的关联性结果显示, 芽狍杆菌纲与 WT 呈正相关, 而黄杆菌纲与其相反. 基于轴 2 的关联性结果显 示, $\alpha$-变形菌纲与 $\mathrm{DO}$ 呈负相关, 与 $\mathrm{COD}$ 和营养盐 $\left(\mathrm{PO}_{4}^{3-}-\mathrm{P} 、 \mathrm{TP} 、 \mathrm{NO}_{3}^{-}-\mathrm{N} 、 \mathrm{NO}_{2}^{-}-\mathrm{N} 、 \mathrm{NH}_{4}^{+}-\mathrm{N} 、 \mathrm{NH}_{3}-\mathrm{N} 、 \mathrm{TN} 、 \mathrm{SiO}_{4}^{2-}-\mathrm{Si}\right)$ 均呈正相关, 而芽狍杆菌纲与其恰好相反. 放线菌纲与 $\mathrm{TP}$ 和 $\mathrm{PO}_{4}^{3-}-\mathrm{P}$ 均呈负相关.

\section{5 珠江下游浮游细菌群落功能预测分析}

功能预测结果 (热图) 显示, 空间分布上大多数样品中, 功能谱的相对丰度是相似的. 转运体 (Transporters)、ABC 转运体 ( $A B C$ transporters)、DNA 修复和重组蛋白 (DNA repair and recombination proteins) 和双组 分系统 (two-component system) 等是珠江下游浮游细菌群落所表达的主要功能. 季节分布上, 丰水期所有站 位的相对丰度高于枯水期,其中转运体和 $\mathrm{ABC}$ 转运体的相对丰度丰水期明显高于枯水期 (图 8). 

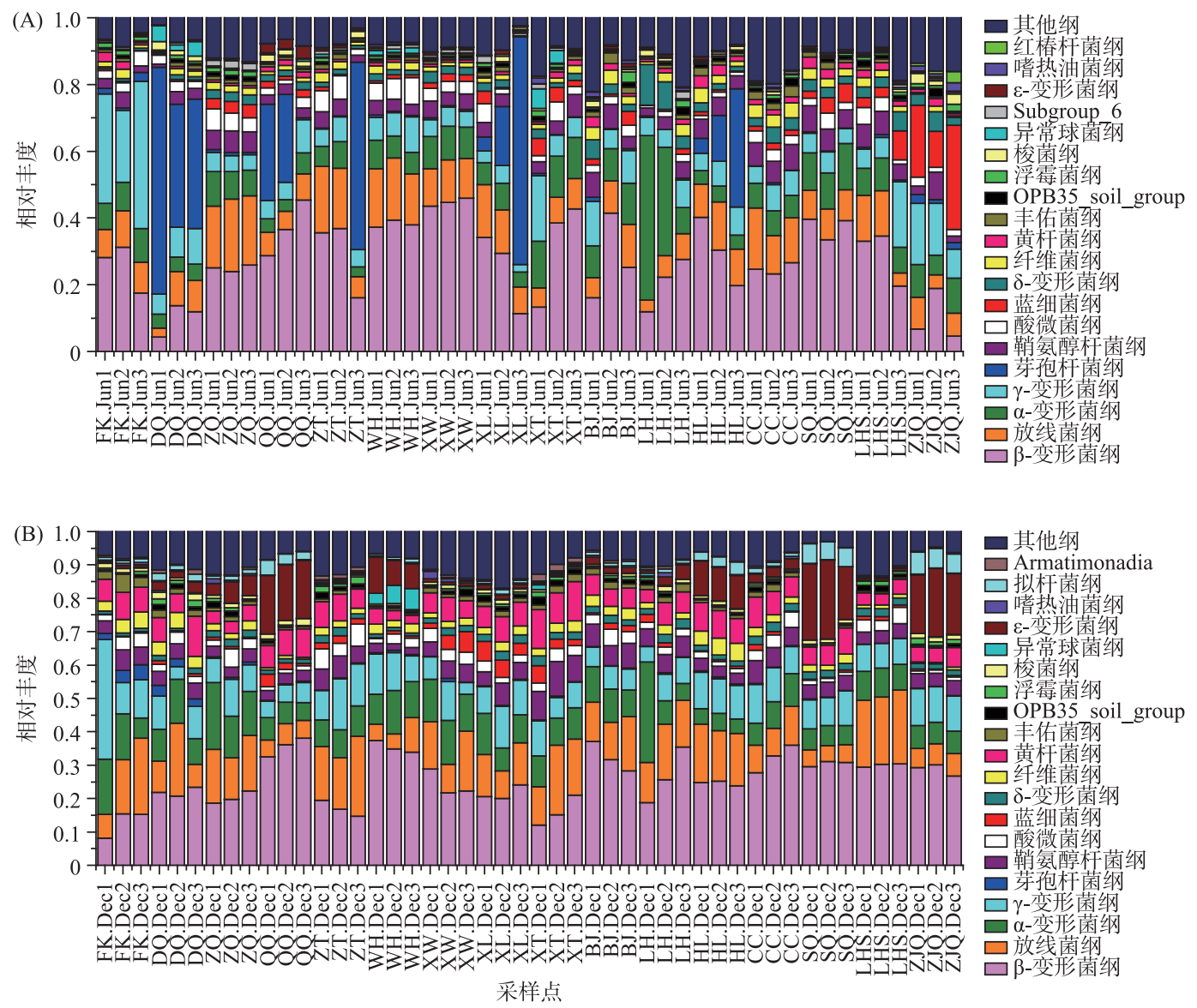

图 3 珠江下游浮游细菌丰水期 (A) 和枯水期 (B) 各纲的相对丰度

(FK.Jun:封开丰水期;FK.Dec:封开枯水期;其他类同)

Fig.3 Relative abundance of each class of bacterioplankton in wet season(A) and dry season (B) in the downstream of Pearl River
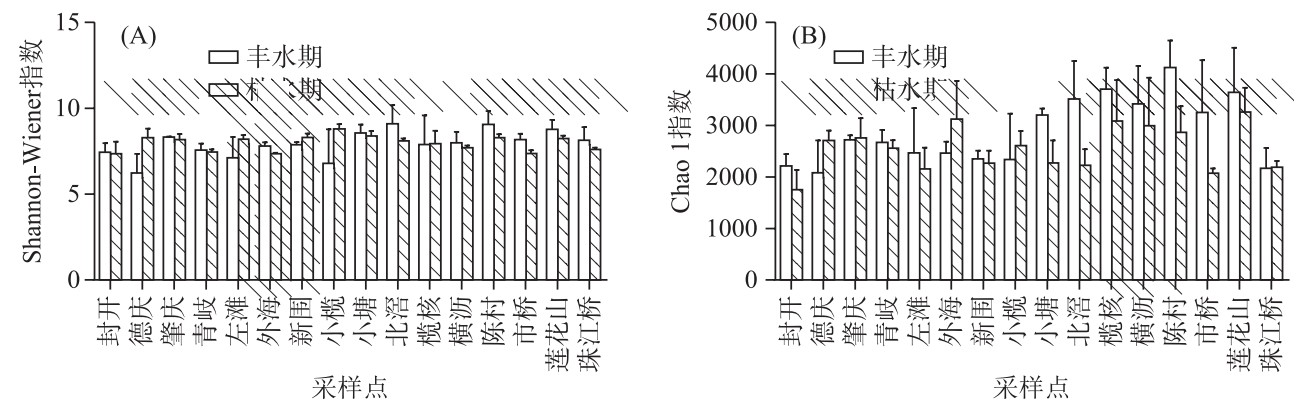

图 4 珠江下游浮游细菌 Shannon-Wiener (A) 和 Chao 1(B) 多样性指数

Fig.4 Shannon-Wiener(A) and Chao 1(B) indexes of bacterioplankton along the downstream of Pearl River 


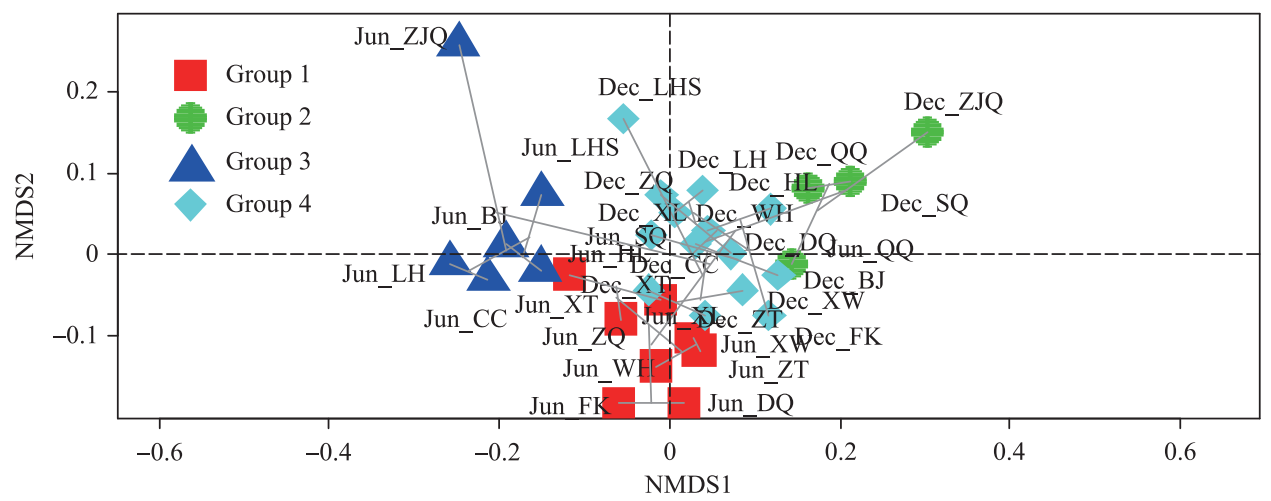

图 5 珠江下游浮游细菌群落 NMDS 分析 (Jun_ZJQ: 丰水期珠江桥,其余类同)

Fig.5 NMDS analysis of bacterioplankton community in the downstream of Pearl River

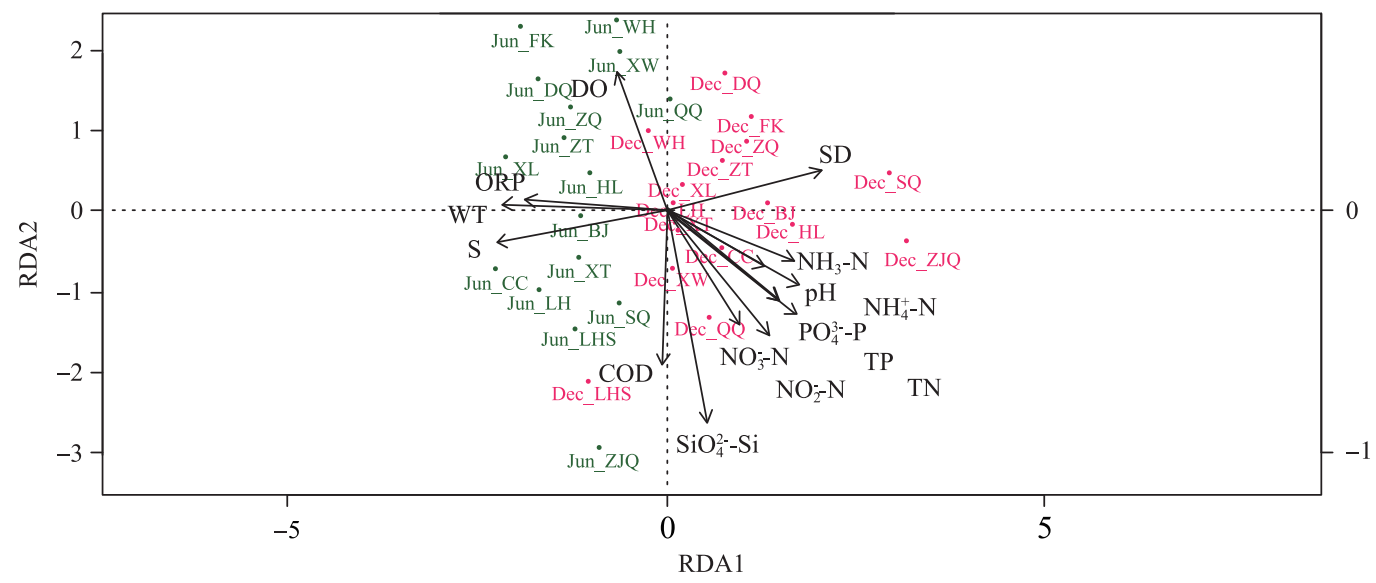

图 6 珠江下游浮游细菌群落与环境因子的 RDA 分析

(Jun_FK : 丰水期封开,其余类同;绿色站位代表丰水期站位,粉色站位代表枯水期站位)

Fig.6 RDA analysis between bacterioplankton community and environment factors in the downstream of Pearl River

\section{3 讨论}

珠江下游浮游细菌群落结构组成显示, 在门分类水平上,变形菌门、放线菌门、拟杆菌门、厚壁菌门、病 微菌门和蓝细菌门是珠江下游的优势菌门. 国内外大型江河生态系统的研究结果 (表 2) 与本研究的结果一 致. 在纲分类水平上, $\beta$-变形菌、放线菌、 $\alpha$-变形菌和 $\gamma$-变形菌的相对丰度在两个季节均排名前四位, 这与国 内外多数淡水生态系统的调查结果也是一致的 ${ }^{[27-30]}$.

本研究结果显示, 浮游细菌群落相似性组成的季节间差异明显, NMDS 结果可以将丰水期和枯水期明显 区分开 (图 5). 纲水平的相对丰度图显示 (图 3), 芽狍杆菌和黄杆菌在两个季节分布差异较明显. RDA 分析 的结果显示, $\mathrm{WT}$ 和 $\mathrm{SD}$ 是影响季节间差异的重要因素 (图 6). $\mathrm{Lv}$ 等 ${ }^{\left[{ }^{[31]}\right.}$ 在黄河三角洲, 以及 $\mathrm{Ma}$ 等 ${ }^{[32]}$ 对海河 的研究均表明, 温度是导致细菌群落结构季节性变化的一个主要原因. 分析认为, 由于每种细菌群落都有自 己的最适温度范围, 且温度可影响细菌的生长速率和新陈代谢 ${ }^{[33-35]}$, 丰水期水温高, 适宜细菌生长, 而枯水 期水温相对较低, 会抑制细菌的增殖和代谢 ${ }^{[36]}$, 从而抑制细菌生长. 芽狍杆菌最适生长温度为 $37^{\circ} \mathrm{C}^{[37]}$, 而此 次采样的 WT 范围为 $18.0 \sim 33.8^{\circ} \mathrm{C}$, 还未达到芽孢杆菌的最适温度, 因此随着 WT 的升高, 芽孢杆菌增加. 而 黄杆菌的最适生长温度为 $25^{\circ} \mathrm{C}{ }^{[38]}$, 低于芽狍杆菌的最适生长温度, 因此两者呈现出的结果不同. 除 WT 的 


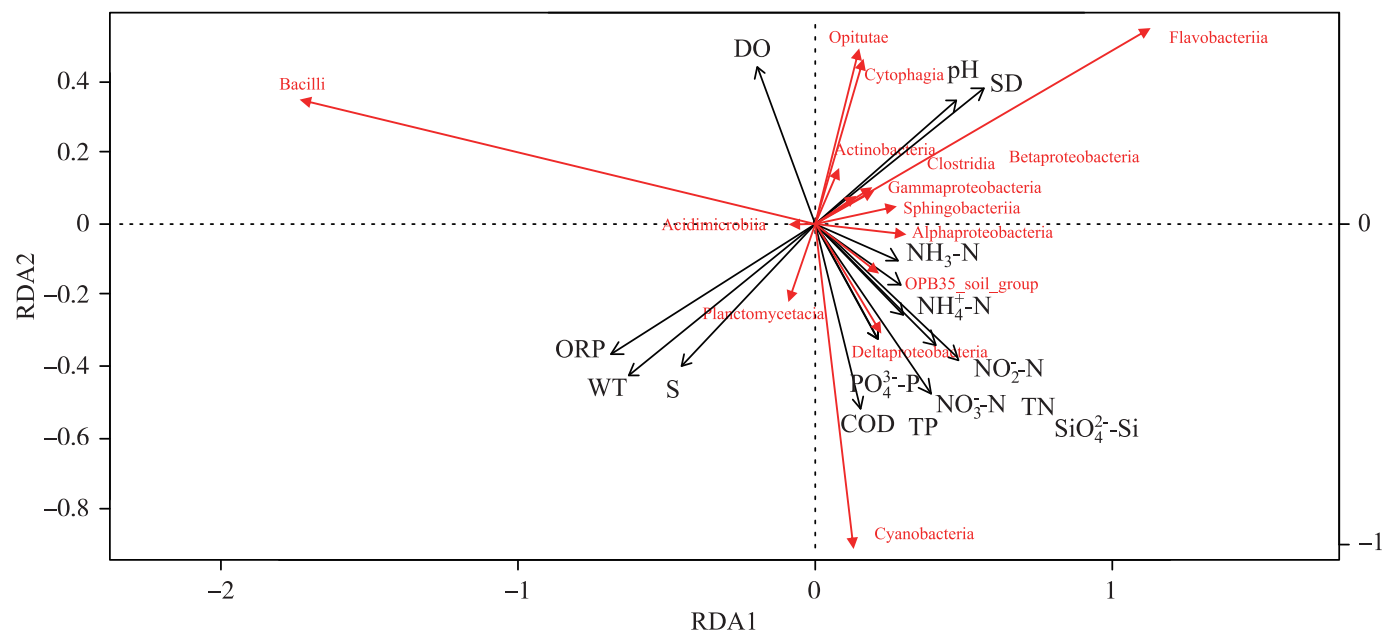

图 7 珠江下游浮游细菌前 15 纲与环境因子的 RDA 分析

Fig.7 RDA analysis between the first 15 classes of bacterioplankton community and environment factors in the downstream of Pearl River

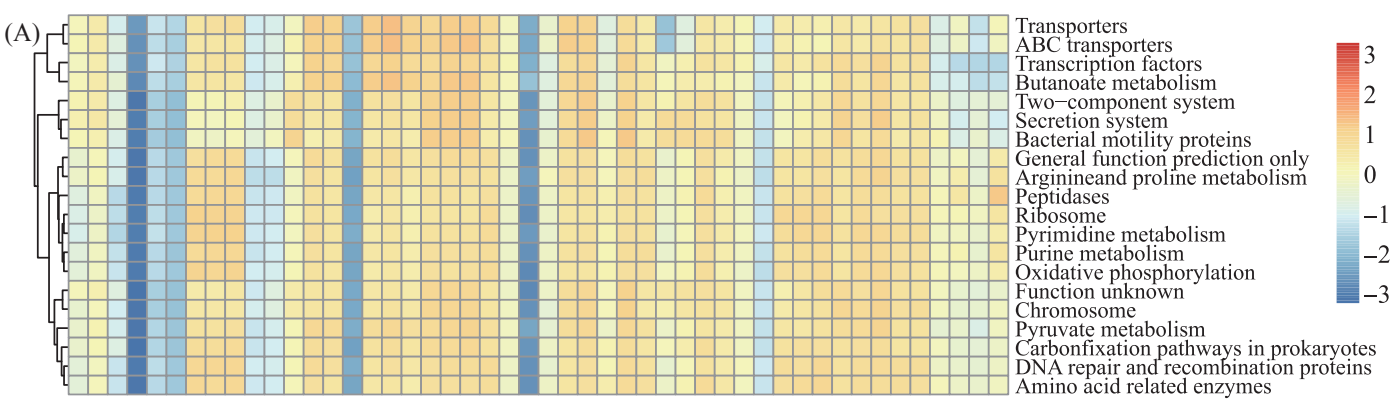

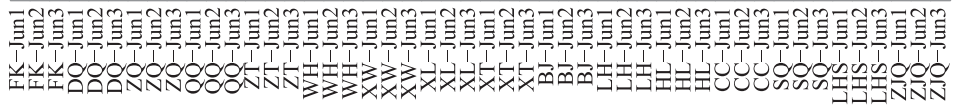

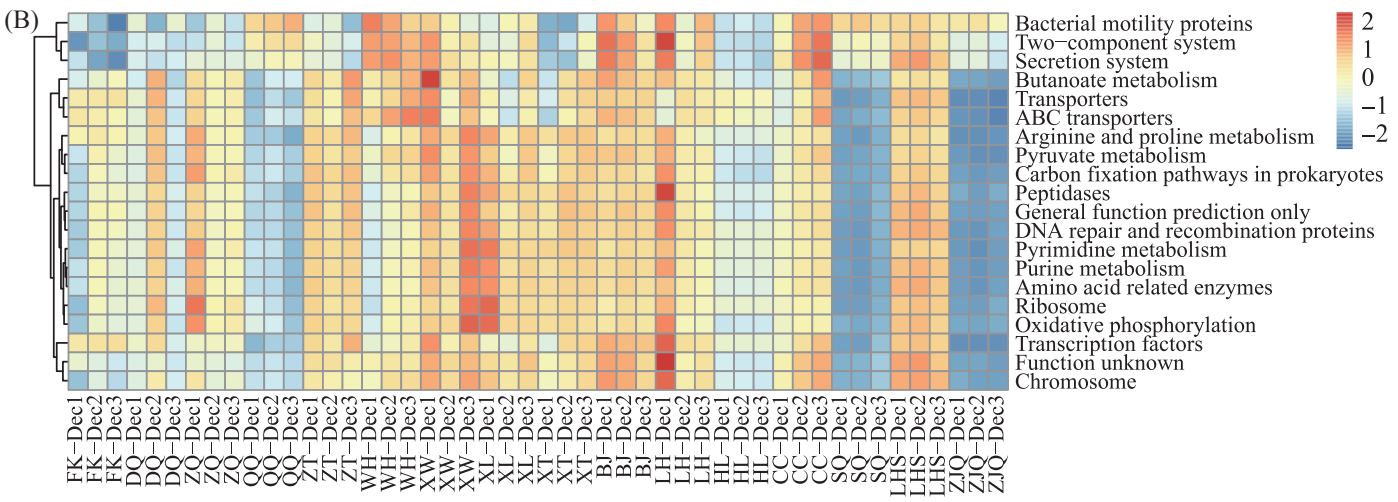

图 8 丰水期 $(\mathrm{A})$ 和枯水期 (B) 细菌功能预测相对丰度热图

Fig.8 Heat map of bacterial function prediction relative abundance in wet season(A) and dry season(B) 
影响外,Jeon 等 ${ }^{[39]}$ 研究发现, 厚壁菌门中的芽孢杆菌纲是沙尘细菌的优势菌群. 丰水期, 大量降雨将山体泥 沙和岸边泥沙卷人河流地表水中, 沙尘细菌的引人从而导致芽狍杆菌纲相对丰度显著提高. 而黄杆菌纲属 拟杆菌门, 拟杆菌门被认为可以降解高分子量有机化合物 ${ }^{[40]}$, 枯水期降雨量减少, 雨水对河流的稀释度降 低, 导致人为输人的有机物含量相对增加, 因此促进了黄杆菌纲的增加. 然而, 相对丰度较高的细菌种群在 两个季节的差异不明显. 分析原因在于: (1) 两个季节的水温差异不大, 平均值相差小于 $10^{\circ} \mathrm{C}$. 寇文伯等 ${ }^{[41]}$ 对鄱阳湖浮游细菌的研究发现, 7 月和 10 月的水温差异不大, 浮游细菌群落的群落结构组成变化也不大. (2) 丰水期频繁降雨导致径流量增大, 水体混合程度高, 透明度降低, 这有助于大量附着细菌进人表层水体, 造成细菌多样性和丰度增加; 然而, 径流量增大对浮游细菌群落也会产生稀释作用, 导致多样性和丰度减 小; 枯水期径流量小, 稀释作用减弱, 但是透明度增大对浮游细菌产生的沉降损失作用增强. 因此从整体上 看细菌群落组成变化显著,但相对丰度较高的细菌种群较稳定,所占比例并没有发生显著变化.

NMDS 结果也显示, 空间分布存在明显差异, 16 个站位可分为 3 个区域: 西江沿线、珠三角河网中部和 广州市周边. 相对丰度图显示, 丰水期放线菌呈西江沿线>河网中部>广州市周边的趋势, $\alpha$-变形菌、 $\gamma$-变形 菌和芽狍杆菌在西江沿线和河网中部个别站位成为最优势菌纲 (图 3A), 蓝细菌在广州市周边站位相对丰 度明显升高; 枯水期 $\beta$-变形菌在西江沿线的相对丰度波动较大,而在河网中部和广州市周边站位较稳定 (图 $3 \mathrm{~B})$. $\mathrm{RDA}$ 结果显示, $\mathrm{DO} 、 \mathrm{COD}$ 和营养盐 $\left(\mathrm{TP} 、 \mathrm{SiO}_{4}^{2-}-\mathrm{Si} 、 \mathrm{PO}_{4}^{3-}-\mathrm{P}\right)$ 是影响空间差异的重要因素. $\mathrm{DO}$ 与大部分西 江沿线和部分河网站位呈正相关 (图 6). 吴娅等 ${ }^{[42]}$ 对三峡库区典型支流的研究也发现, DO 是影响该水域浮 游细菌丰度空间分布的主要限制因子, 分析认为, 不同细菌的最适需氧量不同, DO 浓度高, 适宜好氧菌生 长; 反之, 适宜戻氧菌生长. Newton 等 $^{[43]}$ 的研究发现, 放线菌的丰度往往随着氧浓度的降低而降低; 芽孢杆 菌属好氧细菌, 并能有效减少水体有机物耗氧, 间接增加水体 DO, 降低水中 $\mathrm{COD}^{[44]}$, 因此这 2 种细菌丰度 均随 DO 浓度的升高而升高, 在西江沿线相对丰度较高. 薛彬等 ${ }^{[45]}$ 对 DO 与营养盐 (无机氮、活性磷酸盐) 的 相关性研究表明, DO 与各营养盐无论表底层均呈明显的负相关关系. 营养盐浓度高, 可为细菌提供营养源, 有利于细菌的生长繁殖. 郑金秀等 ${ }^{[46]}$ 对大宁河与香溪河细菌群落分布的研究表明, $\alpha$-变形菌纲与氮、磷呈正 相关, 因此在营养盐浓度较高的榄核, $\alpha$-变形菌纲的相对丰度达到最大值. COD 是衡量水中有机污染物和还 原性无机污染程度的一个综合指标, COD 越高, 说明水中污染物浓度越高, 可为细菌生长提供充足的营养. 分析发现, COD 与珠三角河网中部和广州市周边地区呈正相关. Burkill ${ }^{[47]}$ 和 Iturrlaga 等 $^{[48]}$ 曾报道蓝细菌易 被小型浮游动物捕食, 浮游动物受水质影响较大, 水质恶化, 浮游动物种类减少. 水质监测结果表明, 珠江桥 的 TN 和 DO 均处于劣 $\mathrm{V}$ 类水平, 浮游动物种群减少, 且营养物质充足, 蓝细菌丰度升高, 因此在广州市周边 地区, 蓝细菌丰度达到最高. 营养盐. $\left.\mathrm{TP} 、 \mathrm{SiO}_{4}^{2-}-\mathrm{Si} 、 \mathrm{PO}_{4}^{3-}-\mathrm{P}\right)$ 对浮游细菌群落的影响也很重要. $\mathrm{RDA}$ 结果显 示, $\mathrm{TP}$ 和 $\mathrm{PO}_{4}^{3-}-\mathrm{P}$ 与丰水期西江沿线站位呈负相关, 与枯水期站位和部分丰水期珠三角河网中部和广州市周 边站位呈正相关. 丰水期干流水质较好, 当 $\mathrm{TP}$ 和 $\mathrm{PO}_{4}^{3-}-\mathrm{P}$ 浓度过低, 会限制浮游细菌的生产力和氧消耗. 边 园琦等 ${ }^{[49]}$ 对花神湖和紫霞湖的研究显示, 放线菌在贫营养湖泊水体中占绝对优势. 出现这种情况可能是由 于水体中某一元素可利用量不足以维持异养细菌生长进行生物合成的需要, 限制了放线菌对磷元素的利 用, 因此在 $\mathrm{TP}$ 和 $\mathrm{PO}_{4}^{3-}-\mathrm{P}$ 浓度较低的西江沿线, 放线菌纲相对丰度较大. 在以往研究中, 对 $\mathrm{SiO}_{4}^{2-}-\mathrm{Si}$ 的研究还 很少, 本研究结果显示出, 蓝细菌纲与 $\mathrm{SiO}_{4}^{2-}-\mathrm{Si}$ 浓度呈正相关, 其中赵海萍等 ${ }^{[50]}$ 对渤海湾浮游细菌的研究和 各帅君等 ${ }^{[51]}$ 对辽河口的研究同样表明, 蓝细菌与 $\mathrm{SiO}_{4}^{2-}-\mathrm{Si}$ 浓度呈显著正相关, 因此 $\mathrm{SiO}_{4}^{2-}-\mathrm{Si}$ 对广州市周边站 位影响较大. 相对丰度图显示, 枯水期 $\beta$-变形菌纲在珠三角河网中部和广州市周边相对丰度较稳定, 但在西 江沿线, 波动较大, 这可能是因为枯水期西江沿线径流量大, 水体交换能力强, 因此物种丰度波动较大.

功能预测分析表明, 转运体、 $\mathrm{ABC}$ 转运体、DNA 修复和重组蛋白、双组分系统在细菌功能预测中排名前 四. 转运体和 $\mathrm{ABC}$ 转运体均为细胞膜上的一种蛋白, 参与跨膜运输功能. 其中 $\mathrm{ABC}$ 转运体在细菌中可参与 营养物质的摄取或细菌毒素的分泌 ${ }^{[52]}$. DNA 修复蛋白可随时纠正和修复损伤, 保持 DNA 结构、功能完整 性 ${ }^{[53]}$; DNA 重组又可参与 DNA 修复, 并维持遗传的多样性 ${ }^{[54]}$. 双组分系统信号转导机制, 可应对多种环境 变化、代谢和细胞周期信号,感应 $\mathrm{pH}$ 、养分、氧化还原状态、渗透压力和抗生素的双组分系统等 ${ }^{\left[{ }^{[5]}\right.}$. $\mathrm{Lv}^{\text {等 }}{ }^{[31]}$ 对黄河三角洲功能预测分析表明, 低温细菌群落功能受损. 本研究结果同样显示出, 丰水期所有站位的相对 丰度高于枯水期, 其中转运蛋白和 $\mathrm{ABC}$ 转运蛋白的差异明显. 分析原因 (1) 枯水期温度低, 浮游细菌数量低 
于丰水期, 从而导致功能预测丰度降低. (2) 转运蛋白是一种蛋白质, ABC 转运蛋白是一种 ATP 酶, 温度降 低会抑制蛋白质和酶的活性,微生物群落在低温下活性也较低,降低了微生物代谢 ${ }^{[56]}$.

表 2 国内外基于 $16 \mathrm{~S}$ rRNA 测序的河流细菌群落组成及影响因子研究结果 “

Tab.2 Bacteria communities and the influencing factors in domestic and oversea rivers based on 16S rRNA

\begin{tabular}{|c|c|c|c|c|c|}
\hline 采样时间 & 调查区域 & 样品类型 & 优势群落 & 主要环境因素 & 参考文献 \\
\hline 2016-03 和 2016-09 & 黄河兰州段 & 表层水 & $\begin{array}{l}\text { 枯水期: 拟杆菌>变形菌>蓝细菌 } \\
\text { >放线菌 } \\
\text { 丰水期:变形菌>拟杆菌>放线菌 }\end{array}$ & - & {$[57]$} \\
\hline $2016-11$ & 雅鲁藏布江 & 表层水 & 厚壁菌门,拟杆菌门,变形菌门 & $\begin{array}{l}\text { 可溶性活性磷、海拔、 } \\
\text { 铵态氮、流速、浊度 }\end{array}$ & {$[58]$} \\
\hline $2017-02$ & 澜沧江 & 表层水 & $\begin{array}{l}\text { 变形菌门 }(\alpha, \beta, \gamma) \text { 、拟杆菌门、厚 } \\
\text { 壁菌门 }\end{array}$ & $\begin{array}{l}\text { 水温、溶解氧、浊度、 } \\
\text { 高锰酸盐指数、总氮 }\end{array}$ & {$[59]$} \\
\hline $2015-04-2015-08$ & 赣江南昌段 & 表层水 & $\begin{array}{l}\text { 放线菌门、变形菌门、厚壁菌门、 } \\
\text { 拟杆菌门、蓝藻菌门 }\end{array}$ & 温度、流量、电导率 & {$[27]$} \\
\hline $2016-12$ & 乐安江 & 表层水 & $\beta$-变形菌纲、放线菌门、拟杆菌门 & 溶解氧 & {$[60]$} \\
\hline 2011-03 和 2011-09 & 东江 & 表层水 & 变形菌门、放线菌门、拟杆菌门 & 温度、硝酸盐 & {$[61]$} \\
\hline $2012-11$ & 南明河城区河段 & 表表层水 & $\begin{array}{l}\text { 变形菌门、浮霊菌门、拟杆菌门、 } \\
\text { 酸杆菌门、放线菌门 }\end{array}$ & $\begin{array}{l}\text { 总氮、总磷、砷、镉、 } \\
\text { 录、铅 }\end{array}$ & {$[62]$} \\
\hline $2016-03$ & 南淝河 & 沉积物 & $\begin{array}{l}\text { 变形菌门、绿弯菌门、拟杆菌门、 } \\
\text { 厌氧绳菌纲、 } \gamma \text {-变形菌纲、梭状芽 } \\
\text { 孢杆菌纲、 } \delta \text {-变形菌纲、 } \varepsilon \text {-变形 } \\
\text { 菌纲 }\end{array}$ & $\begin{array}{l}\text { 阳离子交换量、总有 } \\
\text { 机碳、溶解性有机碳、 } \\
\text { 总磷、弱酸浸取态氮、 } \\
\text { 离子交换态氮 }\end{array}$ & {$[63]$} \\
\hline $2011-03$ & 厦门后溪流域 & 表层水 & $\begin{array}{l}\beta \text {-变形菌纲、 } \alpha \text {-变形菌纲、放线菌 } \\
\text { 纲、 } \gamma \text {-变形菌纲、拟杆菌纲 }\end{array}$ & $\mathrm{pH}$ 、总氮 & {$[28]$} \\
\hline $2009-09-2011-04$ & 泰晤士河 & 表层水 & 放线菌门、拟杆菌门、变形菌门 & 亚硝酸盐、硫酸盐、铜 & {$[29]$} \\
\hline $2012-06-2012-07$ & Mooi 河 & 表层水 & $\begin{array}{l}\text { 变形菌门 }(\beta, \alpha, \gamma, \varepsilon, \delta) 、 \text { 拟杆 } \\
\text { 菌门、放线菌门 }\end{array}$ & $\begin{array}{l}\mathrm{pH} \text { 、溶解氧、硫酸盐、 } \\
\text { 叶绿素 } a\end{array}$ & {$[30]$} \\
\hline $2013-07-2013-08$ & 密西西比河 & 表层水 & $\begin{array}{l}\text { 放线菌门、变形杆菌门、拟杆菌 } \\
\text { 门、蓝藻门、浮霉菌门、疮微菌门 }\end{array}$ & - & {$[64]$} \\
\hline
\end{tabular}

*一表示文献中未进行细菌群落影响因子的研究.

\section{4 结论}

1) 珠江下游浮游细菌主要菌门为变形菌门、放线菌门、拟杆菌门、厚壁菌门、疮微菌门和蓝细菌门. 优势 菌纲为 $\beta$-变形菌纲、放线菌纲、 $\alpha$-变形菌纲、 $\gamma$-变形菌纲、芽孢杆菌纲和黄杆菌纲.

2) 珠江下游浮游细菌群落结构存在季节和空间变化,多样性指数丰水期高于枯水期,空间分为 3 个区 域:西江沿线、珠三角河网中部和广州市周边.

$3)$ 水温 $(\mathrm{WT}) 、$ 溶解氧 $(\mathrm{DO})$ 、磷酸盐 $\left(\mathrm{PO}_{4}^{3-}-\mathrm{P}\right)$ 、硅酸盐 $\left(\mathrm{SiO}_{4}^{2-}-\mathrm{Si}\right)$ 、总磷 $(\mathrm{TP})$ 、透明度 $(\mathrm{SD})$ 是驱动细菌 群落变化最显著的环境因子, WT 和 $\mathrm{SD}$ 是影响季节差异的重要因素, $\mathrm{DO} 、 \mathrm{COD}$ 和营养盐 $\left(\mathrm{PO}_{4}^{3-}-\mathrm{P} 、 \mathrm{SiO}_{4}^{2-}-\mathrm{Si}\right.$ 、 TP) 是影响空间差异的重要因素.

4) 功能预测分析表明, 转运体 (Transporters)、ABC 转运体 (ABC transporters)、DNA 修复和重组蛋白 (DNA repair and recombination proteins)、双组分系统(two-component system)、嘌呤代谢 (Purine metabolism) 等是珠江下游浮游细菌群落所表达的主要功能,其中转运体和 $\mathrm{ABC}$ 转运体丰水期明显高于枯水期.

\section{5 参考文献}

[ 1 ] Jiang JG, Shen YF. Development of the microbial communities in Lake Donghu in relation to water quality. Environmental Monitoring and Assessment, 2007, 127(1/2/3) : 227-236. DOI: 10.1007/s10661-006-9275-9. 
[ 2 ] Araya R, Tani K, Takagi T et al. Bacterial activity and community composition in stream water and biofilm from an urban river determined by fluorescent in sity hybridization and DGGE analysis. FEMS Microbiology Ecology, 2003, 43(1) : 111119. DOI: 10.1016/s0168-6496(02)00394-x.

[ 3 ] Li Y, Li DY. Correlation between the distribution of bacterioplankton and the environmental factors in the Yangtze River estuary and its adjacent seas. Marine Science Bulletin, 2007, 26(6) : 9-19. [李云, 李道季. 长江口邻近海域浮游细菌 分布与环境因子的关系. 海洋通报, 2007, 26(6): 9-19.]

[ 4 ] Liu LM, Yang J, Yu XQ et al. Patterns in the composition of microbial communities from a subtropical river: Effects of environmental, spatial and tenmporal factors. PLoS ONE, 2013, 8(11) : 1-10.

[ 5 ] Jordaan K, Bezuidenhout CC. Bacterial community composition of an urban river in the North West Province, South Afri$\mathrm{ca}$, in relation to physico-chemical water quality. Environmental Science and Pollution Research, 2016, 23 (6) : 58685880. DOI: $10.1007 / \mathrm{s} 11356-015-5786-7$.

[ 6 ] Payne JT, Millar JJ, Jackson CR et al. Patterns of variation in diversity of the Mississippi river microbiome over 1,300 kilometers. PLoS ONE, 2017, 12(3) : e0174890. DOI: 10.1371/journal.pone.0174890.

[ 7 ] Liu ZL, Koshikawa H, Ning XR et al. Bacterioplankton production in dilution zone of the Changjiang( Yangtze) Estuary. China Ocean Press, 2001, 20 (1): 131-139.

[ 8 ] Liu Z, Huang S, Sun G et al. Phylogenetic diversity, composition and distribution of bacterioplankton community in the Dongjiang River, China. FEMS Microbiology Ecology, 2012, 80( 1) : 30-44. DOI: 10.1111/j.1574-6941.2011.01268.x.

[ 9 ] Qian Y. The water supply and its development in the Pearl River [Dissertation]. Nanjing: Hohai University, 2005. [ 钱 燕. 珠江水资源利用及发展 [学位论文]. 南京: 河海大学, 2005.]

[10] Wang YP. Characteristics of water quality and heavy metals in guangdong section of the Pearl River Basin [Dissertation]. Guangzhou: South China University of Technology, 2012. [王益平. 珠江流域广东段河水水质和重金属污染特征研究 [学位论文]. 广州: 华南理工大学, 2012.]

[11] Xie WP, Wang SB, Zhu XP et al. Residues and potential ecological risk assessment of metal in sediments from lower reaches and estuary of Pearl River. Environmental Science, 2012, 33(6) : 1808-1815. [谢文平, 王少冰, 朱新平等. 珠江 下游河段沉积物中重金属含量及污染评价. 环境科学, 2012, 33(6) : 1808-1815.]

[12] Han L, Gao ZQ, Bai JH et al. PAHs in surface wetland soils of the Pearl River Delta affected by urbanization: Levels, sources, and toxic risks. Journal of Agro-Environment Science, 2019, 38(3) : 609-617. DOI: 10.11654/jaes.2018-1535. [韩玲, 高照琴, 白军红等. 城市化背景下珠江三角洲典型湿地土壤多环芳烃 ( PAHs) 的含量、来源与污染风险评 价. 农业环境科学学报, 2019, 38(3): 609-617.]

[13] Liu XD, Zhang XY, Liu H. Assessment of water quality and analysis on pollution characteristics in the Pearl River Basin in the past 10 years. Environmental Science Survey, 2018, 37(1):67-70. [刘晓丹, 张雪雁, 刘珩. 珠江流域近 10 a 水 质状况评价及污染特征分析. 环境科学导刊, 2018, 37(1):67-70.]

[14] Wang C, Li XH, Lai ZN et al. Temporal and spatial pattern of the phytoplankton biomass in the Pearl River Delta. Acta Ecologica Sinica, 2013, 33(18) : 5835-5847. DOI：10.5846/stxb201305191112. [王超, 李新辉, 赖子尼等. 珠三角 河网浮游植物生物量的时空特征. 生态学报, 2013, 33(18): 5835-5847.]

[15] Li ZF, Xie J, Wang GJ et al. Community characteristics of the macrozoobenthos and bioassessment of water quality in aquaculture ponds of the Pearl River Delta. J Lake Sci, 2017, 29(4) : 124-134. DOI: 10.18307/2017.0413. [李志斐, 谢骏, 王广军等. 珠江三角洲养殖池塘底栖动物群落结构及水质生物学评价. 湖泊科学, 2017, 29(4): 124-134.]

[16] Caporaso JG, Lauber CL, Walters WA et al. Ultra-high-throughput microbial community analysis on the Illumina HiSeq and MiSeq platforms. The Isme Journal, 2012, 6(8) : 1621-1624. DOI: 10.1038/ismej.2012.8.

[17] Walters W, Hyde ER, Berglyons D et al. Improved bacterial 16S rRNA gene( V4 and V4-5) and fungal internal transcribed spacer marker gene primers for microbial community surveys. Msystems, 2016, 1(1) : e00009-15. DOI: 10.1128/mSystems.00009-15.

[18] Wei JM, Cui LJ, Li W et al. Characteristics of bacterial communities in surface-flow constructed wetlands. Environmental Science, 2016, 37(11) : 4357-4365. DOI: 10.13227/j.hjkx.201602108. [魏佳明, 崔丽娟, 李伟等. 表流湿地细菌群 落结构特征. 环境科学, 2016, 37(11) : 4357-4365.]

[19] Liu Y, Huang YM, Zeng QC. Soil bacterialcommunities under different vegetation types in the Loess Plateau. Environmental Science, 2016, 37(10) : 3931-3938. DOI : 10.13227/j.hjkx.2016.10.035. [刘洋, 黄懿梅, 曾全超. 黄土高原不同 
植被类型下土壤细菌群落特征研究. 环境科学, 2016, 37(10): 3931-3938.]

[20] Chao YQ, Mao YP, Wang ZP et al. Diversity and functions of bacterial community in drinking water biofilms revealed by high-throughput sequencing. Scientific Reports, 2015, 5: 10044.DOI: 10.1038/srep10044.

[21] Caporaso JG, Lauber CL, Walters WA et al. Global patterns of 16S rRNA diversity at a depth of millions of sequences per sample. Proceedings of the National Academy of Sciences, 2011, 108 (Supplement_1): 4516-4522. DOI: 10.1073/ pnas. 1000080107.

[22] Magoc T, Salzberg SL. FLASH: fast length adjustment of short reads to improve genome assemblies. Bioinformatics, 2011, $27(21)$ : 2957-2963. DOI: 10.1093/bioinformatics/btr507.

[23] Caporaso JG, Kuczynski J, Stombaugh J et al. QIIME allows analysis of high-throughput community sequencing data. Nature Methods, 2010, 7(5) : 335-336. DOI: 10.1038/nmeth.f.303.

[24] Edgar RC, Haas BJ, Clemente JC et al. UCHIME improves sensitivity and speed of chimera detection. Bioinformatics, 2011, 27 (16) : 2194. DOI: 10.1093/bioinformatics/btr381.

[25] Edgar RC. UPARSE: highly accurate OTU sequences from microbial amplicon reads. Nature Methods, 2013, 10(10): 996. DOI: 10.1038 /NMETH.2604.

[26] Quast C, Pruesse E, Yilmaz P et al. The SILVA ribosomal RNA gene database project: improved data processing and webbased tools. Nucleic Acids Research, 2013, 41(D1) : 590-596. DOI: 10.1093/nar/gks1219.

[27] Wang P, Chen B, Li CQ et al. Bacterial communities in Nanchang section of the Ganjiang River in wet seaon. China Environmental Science, 2016, 36(8) : 2453-2462. [王鹏, 陈波, 李传琼等. 赣江南昌段丰水期细菌群落特征. 中国环境 科学, 2016, 36(8): 2453-2462.]

[28 ] Liu LM, Yang J, Yu XQ et al. Bacterioplankton diversity in Xiamen Houxi river watershed along an urban-rural gradient and its relation to environmental factors. Chinese Journal of Appled and Environmental Biology, 2012, 18(4) : 591-598. DOI : 10.3724/SP.J.1145.2012.00591. [刘乐冕, 杨军, 余小青等. 厦门后溪流域沿城乡梯度浮游细菌多样性及其 与环境因子的关系. 应用与环境生物学报, 2012, 18(4): 591-598.]

[29] Read DS, Gweon HS, Bowes MJ et al. Catchment-scale biogeography of riverine bacterioplankton. The ISME Journal, 2015, 9(2) : 516-526. DOI: 10.1038/ismej.2014.166.

[30 J Jordaan K, Bezuidenhout CC. Bacterial community composition of an urban river in the North West Province, South Africa, in relation to physico-chemical water quality. Environmental Science and Pollution Research, 2016, 23 (6) : 58685880. DOI: $10.1007 / \mathrm{s} 11356-015-5786-7$.

[31] Lv XF, Ma B, Yu J et al. Bacterial community structure and function shift along a successional series of tidal flats in the Yellow River Delta. Scientific Reports, 2016, 6: 36550. DOI : 10.1038/srep36550.

[32] Ma LL, Mao GN, Liu J et al. Spatial-temporal changes of bacterioplankton community along an exhorheic river. Frontiers in Microbiology, 2016, 7: 250. DOI: 10.3389/fmicb.2016.00250.

[33] Adams HE, Crump BC, Kling GW. Temperature controls on aquatic bacterial production and community dynamics in arctic lakes and streams. Environmental Microbiology, 2010, 12(5): 1319-1333. DOI: 10.1111/j.1462-2920.2010.02176.x.

[34] Sieburth JM. Seasonal selection of estuarine bacteria by water temperature. Journal of Experimental Marine Biology and Ecology, 1967, 1(1) : 98-121. DOI: 10.1016/0022-0981(67)90009-3.

[35] Xiao H, Zhang Z, Zhang Y et al. Distribution characteristics of bacterioplankton in spring and autumn in costal waters of south Shandong. Periodical of Ocean University of China, 2009, 39(4) : 652-656. [肖慧, 张吉, 张艳等. 春秋季山东南 部近岸浮游细菌生态分布. 中国海洋大学学报, 2009, 39(4) : 652-656.]

[36] Cao XY, Xu HM, Wang SC et al. Seasonal variation of bcaterioplankton community structure and its relationship with environmental factors of Mochou Lake and Zixia Lake in Nanjing. Chemistry and Bioengineering, 2016, 33(12) : 19-26. [曹 新益, 徐慧敏, 王司辰等. 南京莫愁湖与紫霞湖浮游细菌群落结构的季节性变化及其与环境因子的关系. 化学与 生物工程, 2016, 33(12): 19-26.]

[37] Yang YH, Li SC, Hu Y et al. Research on growth conditions and physiological tolerance features of Bacillus species AF1 with multifunction. Journal of Chongqing University of Technology: Natural Science, 2015, 29(8) : 78-83. [杨艳红, 李 世川, 胡燕等. 多功能芽狍杆菌 AF1 的生长条件与生理耐受特性研究. 重庆理工大学学报: 自然科学版, 2015, 29 (8) : 78-83.]

[38] Leng Y. Diversity and potential applications of the Yak Dung-Degrading Microbes in the Qinghai-Tibet Plateau [ Disserta- 
tion]. Lanzhou: Lanzhou Jiaotong University, 2014. [冷艳. 青藏高原牦牛粪降解微生物多样性及其应用研究 [ 学位 论文]. 兰州: 兰州交通大学, 2014.]

[39] Jeon EM, Kim HJ, Jung K et al. Impact of Asian dust events on airborne bacterial community assessed by molecular analyses. Atmospheric Environment, 2011, 45(25) : 4313-4321. DOI: 10.1016/j.atmosenv.2010.11.054.

[40 ] Drury B, Rosi-Marshall E, Kelly JJ. Wastewater treatment effluent reduces the abundance and diversity of benthic bacterial communities in urban and suburban rivers. Applied and Environmental Microbiology, 2013, 79(6) : 1897-1905. DOI: 10. 1128/AEM.03527-12.

[41] Kou WB. Transition in bacterial communities among hydrological changes and different regions in the surface water of Poyang Lake [Dissertation]. Nanchang: Nanchang University, 2016. [寇文伯. 鄱阳湖表层水体细菌群落在不同水文时 期、不同区域间的变化 [学位论文]. 南昌: 南昌大学, 2016.]

[42] Wu Y, Wang YC, Hu MM et al. Ecological distribution and its influencing factors of bacterioplankton in the typical tributaries of Three Gorges Reservoir. Chinese Journal of Ecology, 2016, 34(4) : 1060-1065. [吴娅, 王雨春, 胡明明等. 三 峡库区典型支流浮游细菌的生态分布及其影响因素. 生态学杂志, 2016, 34(4) : 1060-1065. ]

[43] Newton RJ, Jones SE, Eiler A et al. A guide to the natural history of freshwater lake bacteria. Microbiology and Molecular Biology Reviews, 2011, 75(1) : 14-49. DOI: 10.1128/MMBR.00028-10.

[44] Hu YM, Ge XY, Liang YX. Water purification functions of the strain Bacillus subtilis FY99-01. Journal of Huazhong Agricultural University, 2006, 25(4): 404-407. [胡咏梅, 葛向阳, 梁运祥. 枯草芽孢杆菌 FY99-01 菌株的净水作用. 华 中农业大学学报, 2006, 25(4): 404-407.]

[45] Xue B, Zhu JP, Li TJ et al. Distribution of dissolved oxygen and nutrients and its relationship around shengsi islands of Zhejiang. Guangzhou Chemical Industry, 2016, 44(17): 150-151. [薛彬, 朱敬萍, 李铁军等. 嵊泗海域溶解氧与营 养盐分布特征及其相关性研究. 广州化工, 2016, 44(17)：150-151.]

[46] Zheng JX, Hu JX, Chi SY et al. Distribution of bacterial communities in Daning River and Xiangxi River. Environmental Science \& Technology, 2016, 39(8): 171-177. [郑金秀, 胡菊香, 池仕运等. 大宁河与香溪河细菌群落分布. 环境 科学与技术, 2016, 39(8): 171-177.]

[47] Burkill PH, Leakey RJG, Owens NJP et al. Synechococcus and its importance to the microbial foodweb of the northwestern Indian Ocean. Deep Sea Research Part II: Topical Studies in Oceanography, 1993, 40(3) : 773-782. DOI : 10.1016/09670645 ( 93 ) 90057-T.

[48] Iturriaga R, Mitchell BG. Chroococcoid cyanobacteria: a significant component in the food web dynamics of the open ocean. Marine Ecology Progress, 1986, 28(3) : 291-297. DOI: 10.3354/meps028291.

[49] Bian YQ, Xing P, Li HB et al. Analysis on bacterioplankton community structure in two oligotrophic lakes, Huashen Lake and Zixia Lake. Ecological Science, 2010, 29(2): 109-115. [边园琦, 邢鹏, 李化炳等. 贫营养湖泊花神湖和紫霞湖 浮游细菌群落结构分析. 生态科学, 2010, 29(2) : 109-115.]

[50] Zhao HP, Li QX, Tao JH. Distribution characteristics of bacterioplankton in Bohai Bay and its environmental influence factors. Water Resources Protection, 2018, 34(5): 92-98. [ 赵海萍, 李清雪, 陶建华. 渤海湾浮游细菌分布特征及环境 影响因素. 水资源保护, 2018, 34(5): 92-98.]

[51] Zan SJ, Fan JF, Ming HX et al. Associated and free-living bacteria community structure and diversity of Liaohe estuary. Marine Environmental Science, 2016, 35(4) : 594-599. [备帅君, 㚞景风, 明红霞等. 辽河口浮游细菌和附着细菌群 落结构及多样性分析. 海洋环境科学, 2016, 35(4) : 594-599.]

[52] Feng ZY, Liu DF, Cui YD. Progress on research of ATP-binding cassette transporters in Escherichia coli. Chinese Journal of Zoonoses, 34(10): 86-91，102. [冯振月, 刘德福, 崔玉东. 大肠杆菌 ABC 转运体研究进展. 中国人兽共患病学 报, 2018, 34(10): 86-91, 102.]

[53] Dong YP, Zhang D, Han SX. Recent advances in DNA damage repair mechanism. Chinese Journal of Radiation Oncology, 2017，26(9) : 1103-1108. [董怡萍, 张丹, 韩苏夏. DNA 损伤修复机制的研究进展. 中华放射肿瘤学杂志, 2017, 26(9): 1103-1108.]

[54] Tang BH ed. Medical molecular biology. Beijing: China Traditional Chinese Medicine Press, 2014: 48-53. [唐炳华. 医 学分子生物学. 北京: 中国中医药出版社, 2014: 48-53.]

[55] Hao YH, Zhang W, Chen M. Research progress on two component system of bacteria. Journal of Agricultural Science and Technology, 2012, 14(2) : 67-72. [郝艳华, 张维, 陈明. 细菌双组分系统的研究进展. 中国农业科技导报, 2012, 
14(2): 67-72.]

[56] Yu Y, Wang H, Liu J et al. Shifts in microbial community function and structure along the successional gradient of coastal wetlands in Yellow River Estuary. European Journal of Soil Biology, 2012, 49: 1-21. DOI: 10. 1016/j. ejsobi. 2011. 08.006 .

[57] Zhao MM, Fan TT, Xue LG. Water quality monitoring in Lanzhou section of the Yellow River based on diversity of the Planktonic bacteria system. Journal of Lanzhou Jiaotong University, 2018, 37(2) : 98-103. [ 赵萌萌, 范桃桃, 薛林贵. 基于浮游细菌系统多样性的黄河兰州段水质检测. 兰州交通大学学报, 2018, 37(2): 98-103.]

[58] Wang P, Wang X, Wang C et al. Shift in bacterioplankton diversity and structure: Influence of anthropogenic disturbances along theYarlung Tsangpo River on the Tibetan Plateau, China. Scientific Reports, 2017, 7(1) : 12529. DOI: 10.1038/ s41598-017-12893-4.

[59] Cheng B, Wang X, Xu YQ et al. Bacterioplankton community structure in the Lancang River Basin and the analysis of its driving environmental factors. Environmental Science, 2018, 39(8) : 186-196. DOI: 10.13227/j.hjkx.201711014. [ 程 豹, 望雪, 徐雅倩等. 澜沧江流域浮游细菌群落结构特征及驱动因子分析. 环境科学, 2018, 39(8): 186-196.]

[60] Xiao HY, Wang P, Liu JZ et al. Characteristics of bacterial community in Le' an River in winter based on high-throughput sequencing. Acta Microbiologica Sinica, 2019, 59(1) : 187-200. [肖汉玉, 王鹏, 刘君政等. 基于高通量测序的乐安 江冬季细菌群落特征分析. 微生物学报, 2019, 59(1): 187-200.]

[61] Sun W, Xia C, Xu M et al. Seasonality affects the diversity and composition of bacterioplankton communities in Dongjiang river, a drinking water source of Hong Kong. Frontiers in Microbiology, 2017, 8: 1644. DOI: 10.3389/fmicb.2017.01644.

[62] Tang J, Xu XR, Shang CY et al. Association of bacterial diversity in city area of Nanming river with environmental factors. Acta Microbiologica Sinica, 2015, 55(8): 95-104. [唐婧, 徐小蓉, 商传禹等. 南明河城区河段细菌多样性与环境因 子的关系. 微生物学报, 2015, 55(8): 95-104.]

[63] Yang CM, Wu YQ, Wang YL et al. Microbial community structure characteristics and its key driving factors in surface sediments along Nanfei River. China Environmental Science, 2018, 38(9): 3552-3561. [杨长明, 吴亚琼, 王育来等. 南淝 河表层沉积物细菌群落结构特征及驱动因素. 中国环境科学, 2018, 38(9) : 3552-3561.]

[64] Payne JT, Millar JJ, Jackson CR et al. Patterns of variation in diversity of the Mississippi river microbiome over 1,300 kilometers. PLoS ONE, 2017, 12(3) : e0174890. DOI: 10.1371/journal.pone.0174890. 